International Journal of Instruction e-ISSN: 1308-1470 • www.e-iji.net
April 2019 • Vol.12, No.2

p-ISSN: 1694-609X

pp. 651-666

Received: 23/09/2018

Revision: 24/02/2019

Accepted: 01/03/2019

OnlineFirst:17/03/2019

\title{
Influence of Moderating Variables on Nigerian Undergraduates' Emotional Intelligence and Attitude towards Examination
}

\section{Lateef Omotosho Adegboyega}

Ph.D, Department of Counsellor Education, Faculty of Education, University of Ilorin, Ilorin, Nigeria, adegboyega.lo@unilorin.edu.ng

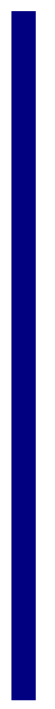

This paper investigated the influence of moderating variables on Nigerian undergraduates' emotional intelligence and attitude towards examination. Descriptive survey of the correlational type was employed for the study. One thousand, five hundred and thirty-six $(1,536)$ undergraduates in Nigeria were drawn using purposive and stratified sampling techniques. Two null hypotheses were generated and tested at 0.05 level of significance. "Emotional Intelligence Scale" (EIS) and "Attitude Towards Examination Scale" (ATES) were the instruments used to collect relevant data. The findings revealed that there was a significant correlation between emotional intelligence and attitude of Nigerian undergraduates towards examination. The findings also revealed that gender, age, level of study, university and family type had a significant positive influence on undergraduates' emotional intelligence and attitude towards examination in Nigeria. It was therefore recommended, among others, that students should continue to cultivate the habit of developing high emotional intelligence as it would help them to develop positive attitude towards examination, effective leadership skills such as improved communication among peers and other people, less school and workplace conflict, better problem-solving skills and increased likelihood of promotions to greater heights.

Keywords: emotional intelligence, attitude towards examination, undergraduates, Nigeria, examination

\section{INTRODUCTION}

An attitude is an expression of favour or disfavour toward a person, place, thing, or event (the attitude object). Prominent psychologist Allport (1935) once described attitude as the most distinctive and indispensable concept in contemporary social psychology. Attitude can be formed from a person's past and present. Is also measurable and changeable as well as influencing the person's emotion and behaviour.

Citation: Adegboyega, L. O. (2019). Influence of Moderating Variables on Nigerian Undergraduates' Emotional Intelligence and Attitude towards Examination. International Journal of Instruction, 12(2), 651-666. https://doi.org/10.29333/iji.2019.12241a 
An attitude can be defined as a positive or negative evaluation of people, objects, event, activities, ideas, or just about anything in your environment; but there is debate about precise definitions. Eagly and Chaiken (1998) defined attitude as a psychological tendency that is expressed by evaluating a particular entity with some degree of favour or disfavour. Though, it is sometimes common to define an attitude as affect toward an object; affect (i.e., discrete emotions or overall arousal) is generally understood to be distinct from attitude as a measure of favorability (Ajzen, 2001).

This definition of attitude allows for one's evaluation of an attitude object to vary from extremely negative to extremely positive; but it admits that people can also be conflicted or ambivalent toward an object meaning that they might at different times express both positive and negative attitude toward the same object. This has led to some discussion of whether individual can hold multiple attitudes toward the same object (Porterfield \& Kleiner, 2005). Whether attitudes are explicit (deliberately formed) or implicit (subconscious) has been a topic of considerable research. Research on implicit attitudes, which are generally unacknowledged or outside of awareness, uses sophisticated methods involving people's response times to stimuli to show that implicit attitudes exist (perhaps in tandem with explicit attitudes of the same object). Implicit and explicit attitudes seem to affect people's behaviour, though in different ways. They tend not to be strongly associated with each other; although, in some cases they are. The relationship between them is poorly understood.

An examination, commonly known as exam, is a test to see how good somebody is at something. In its widest sense, to examine somebody or something is to look at it very carefully; perhaps to find out why something is not working properly. Someone who is ill may need to go to a doctor to have a medical examination. A machine that is not working properly may need an examination to find out the cause of the problem (Goswami, 1991).

In education, an examination is a test to show the knowledge and ability of a student. A student who takes an examination is a candidate. The person who decides how well the student has performed is the examiner. An examination may be a written test, an onscreen test or a practical test. Examples of a practical test may be: driving a car, speaking a language, playing a musical instrument or doing a scientific experiment. An on-screen test is a test which uses the computer. For the candidate to be successful he would have passed the examination; and if otherwise, he would have failed. In some cases it is possible for a student who has failed to take the exam again another time.

An examination is an assessment intended to measure a test-taker's knowledge, skill, aptitude, physical fitness, or classification in many other topics (e.g., beliefs) (Goswami, 1991). An examination can be administered orally, on paper, on a computer, or in a confined area that requires a test taker to physically perform a set of skills. Tests vary in style, rigour and requirements. A test may be administered formally or informally. An example of an informal test would be a reading test administered by a parent to a child; while an example of a formal test would be a final examination administered by a teacher in a classroom or an I.Q. test administered by a psychologist in a clinic. Formal testing often results in a grade or a test score (Goswami, 1991). 
An examination which is also referred to as a test could be either a standardized or nonstandardized test. A standardized test is any test that is administered and scored in a consistent manner to ensure legal defensibility; while a non-standardized test is usually flexible in scope and format, variable in difficulty and significance (Goswami, 1991). Since these tests are usually developed by individual instructors, the format and difficulty of these tests may not be widely adopted or used by other instructors or institutions. A non-standardized test may be used to determine the proficiency level of students, to motivate students to study, and to provide feedback to students.

Evidence abounds of increasing incidents of examination malpractices by students at schools and colleges which conflict with the core purpose of education. The training of the mind and character for the acquisition of practical and theoretical skills, knowledge and functional ideas for development; and the search for truth and knowledge and the creation and communication of ideas (Peterson, 1988; Aaron, 1992; Nanna, 1997).

Examination in this study means sessional examination, that is, both first and second semester examinations. School examinations are tools for measuring learners' mastery of content and instructors' effectiveness in delivering the content at different levels of schooling all over the world. According to Ongeri (2009), examinations are also used for placing students in various institutions and jobs; and provide feedback in the teaching and learning processes and curriculum delivery in general. In Kenya, examinations are conducted from nursery schools through primary schools, secondary schools, tertiary colleges and universities. Students are expected to be honest when taking examinations, but research has shown that due to negative attitude and poor preparations for examinations, some students cheat in examinations (Mitukaa, 2001).

Emotion is a common component in persuasion, social influence, and attitude change. Much of attitude research emphasized the importance of affective or emotion components. Emotion works hand-in-hand with the cognitive process, or the way we think about an issue or situation. Emotional appeals are commonly found in advertising, health campaigns and political messages. Recent examples include: no-smoking health campaigns and political campaign advertising emphasizing the fear of terrorism. Attitudes and attitude objects are functions of cognitive, affective and conative components. Attitudes are part of the brain's associative networks; the spider-like structures residing in long term memory that consists of affective and cognitive nodes.

By activating an affective or emotion node, attitude change may be possible; though affective and cognitive components tend to be intertwined. In primarily affective networks, it is more difficult to produce cognitive counter-arguments in the resistance to persuasion and attitude change. Affective forecasting, otherwise known as intuition or the prediction of emotion, also impacts attitude change. Research suggests that predicting emotion is an important component of decision making, in addition to the cognitive processes. How we feel about an outcome may override purely cognitive rationales.

The construct of emotional intelligence was first defined in the germinal work of Salovey and Mayer in 1990 as the skill by which individuals, through understanding and 
differentiating their emotional states, leverage that knowledge in social interactions (Feyerherm \& Rice, 2002). Emotional intelligence, the ability to understand people and human interactions (Goleman, 1995), has become a significant factor, even surpassing cognitive intelligence, for effective performance at all levels within organizations (Goleman, 1998; Porterfield \& Kleiner, 2005).

Emotional intelligence can be learned (Goleman, 1995, 1998, 2004; Vitello-Cicciu, 2003; Caruso \& Salovey, 2004). Enhanced emotional intelligence consists of five components which are: (a) self-awareness, (b) self-regulation, (c) motivation, (d) empathy, and (e) social skill.

Goleman (1998) opined that passion, compassion, and empathy, as fulcrum points of emotional intelligence, depend on the individual's ability to manage emotions.

The present study sought to investigate the relationship between emotional intelligence and Nigerian undergraduates' attitude towards examination. The moderating variables of gender, age, level of study, university and family type was also part of the investigation.

\section{Research Hypotheses}

The following null hypotheses were formulated and tested in the study:

1. There is no significant correlation between emotional intelligence and attitude of undergraduates towards examination.

2. Gender, age, level of study, university and family type will not influence undergraduates' emotional intelligence and attitude towards examination.

\section{REVIEW OF THE RELATED LITERATURE}

\section{Emotional Intelligence and Performance in Examination}

Emotional intelligence is the capacity for recognizing our own feelings and those of others, for motivating ourselves, and for managing emotions well in us and in our relationship through his research he showed that emotional intelligence is highly beneficial in the areas of education, work, and mental health (Goleman, 1995). Goleman suggested as well as provided research evidences that when it comes to long-term success and success in varied life situations, being high in emotional intelligence is more important than being high in academic abilities. It is claimed about IQ; we can teach and improve in children some crucial emotional competencies. Emotionally intelligent people are more likely to succeed in everything they undertake.

Emotional intelligence is a confluence of developed abilities to (1) know and value self (2) build and maintain a variety of strong, productive and healthy relationships (3) get along and work well with others in achieving positive results; (4) and effectively deal with the pressures and demands of daily life and work. The development of emotional intelligence is an intentional, active and engaging process (Nelson, \& Low, 2003). Affective learning requires a person-centred process for student's growth and development. When emotional intelligence skills are the focus of learning, students are building human development behaviours that are intricately related to the positive outcomes of achievement, goal achievement and personal well- being. Since 1990, Peter 
Salovey and John D. Mayer have been the leading researchers on emotional intelligence. In their influential article "Emotional Intelligence," they defined emotional intelligence as, "the subset of social intelligence that involves the ability to monitor one's own and others' feelings and emotions, to discriminate among them and to use this information to guide one's thinking and actions". Emotional Intelligence is not, in itself, sufficient to create optimal outcomes for youth. However, the way of emotional intelligence being used, both by youth and those who support them has a powerful effect on their lives. Emotional Intelligence appears to be a core ingredient that, when developed and well employed, has wide- ranging benefits for learning, relationships, and wellness (Six Seconds, Emotional Intelligence Network, 2013).

Good academic performance is undoubtedly a research after the heart of educational psychologists. In their attempt to investigate what determines academic outcomes of learners, they have come with more questions than answers. In recent times, a prior literature has shown that learning outcomes (academic achievement and academic performance) have been determined by such variables as family, school, society and motivational factors (Aremu, 2004). In the same vein, Parker, et al., (2004) noted that much of the previous studies have focused on the impact of demographic and socio psychological variables on academic performance.

\section{Attitude and Performance in Examination}

Student's academic performance occupies a very important place in education as well as in the learning process. It is considered as a key criterion to judge one's total potentialities and capacities (Nuthana \& Yenagi, 2009) which are frequently measured by the examination results. It is used to pass judgment on the quality of education offered by academic institutions. In fact, it is still the most topical debate in higher learning institutions that caused great concern to educators and researchers due to the alarming examination performance of students.

In the report of the Professional Regulation Commission (PRC) on performance of graduates in the different licensure and board examinations, data show that performance of graduates has been declining in the last ten years (Mendezabal, 2013). The overall passing rates are quite low (around 36\% on the average). In the 2010 professional licensure examinations given by the PRC, almost 70 percent of college graduates in the country failed and, last year, only 125,419 of the 345,182 or 36.3 percent college and technical school graduates passed their respective professional eligibility examinations as per PRC records. These statistics were based on the results of licensure examinations for 45 groups of professionals. Among the lowest number of passing rates were posted by: elementary teachers (15.4 percent); secondary teachers (23.3 percent); electronics engineers (23.5 percent); and registered electrical engineers (31.9 percent) (Philippine Education Sector Assessment Project, 2011). What explains these performance discrepancies? Multiple reports indicate that academic success cannot be predicted by a single variable. It is dependent upon many factors; both cognitive and non-cognitive.

Students' Academic Performance: academic performance of students has been the subject of intensive research over the past years. It has become an issue of standards and 
quality in education as judged from the performance of students in national licensure and board examinations. However, various reports have documented the poor examination performance of students. For example the report of the PRC on performance of graduates in the different licensure and board examinations which has been declining in the last ten years. The overall passing rates are quite low (around 36\% on the average) (Mendezabal, 2013). In the 2010 professional licensure examinations given by the PRC, almost 70 percent of college graduates in the country failed and, last year, only 125,419 of the 345,182 or 36.3 percent college and technical school graduates passed their respective professional eligibility examinations, as per PRC records. This statistics were based on the results of licensure examinations for 45 groups of professionals. Among the lowest number of passing rates were posted by: elementary teachers (15.4 percent); secondary teachers (23.3 percent); electronic engineers (23.5 percent); and registered electrical engineers (31.9 percent) (Philippine Education Sector Assessment Project, 2011). Other report provided data about education standard; indicating that deterioration had occurred in all fields of education in the society.

\section{Factors Affecting Emotional Intelligence and its Effect on Academic Performance}

Emotional intelligence is a construct and also the independent variable in this study while moderating variables are gender, age, level of study, university and family type which sought the influence of emotional intelligence on undergraduates' attitude towards examination.

There are two factors that affect emotional intelligence. These are: (i) Genetic/Hereditary factors and (ii) Environmental factors. For the purpose of this study, attention was given to the environmental factors (moderating variables).

Gender Differences: this deals with the role of emotional intelligence as it relates to gender. Porter and Stone (1995) stated that female focus more on interpersonal relationship while male were more interested in work-related and miscellaneous problems. In other words, female students displayed more acuity to problems associated with interpersonal relations than male students did. Male students had relatively little concern for interpersonal conflicts "(e.g. personality conflicts)" (Sutarso \& Toto, 1996). According to Kafetsios (2004), female students are superior on the branch of perception of emotion and experimental for example, female students are more accurate in decoding facial expression than male students. Yet, as overall EQ scores, there is no significant difference between genders. Miller, Siliverman and Falk (1994) looked at gender differences in emotional development and found that female scored higher on "emotional potential" and their level of emotional development while male was higher on intellectual potential (Sitoiso \& Toto, 1990).

In a 2001 interview with other researchers, Goleman attributed the gender difference of emotional intelligence to the current culture. Goleman suggested that females are raised to be sensitive to people's feelings which give them a better grasp of empathy. On the other hand, male are better at distracting themselves during the turbulent times (for example, going to a ball game) while female students contemplate their current distressing situation. Bernet (1996) found that female students scored higher than male 
did in two of the three primary areas he tested. In terms of intrapersonal understanding, female tended to score slightly higher. Also, he included in the interpersonal skills the "emphasis on evaluation" where one is measured by the ability to reflect and understand what is happening to oneself from the viewpoint of an outside observer.

Female students scored moderately lower in the area Bernet calls "looking to logic". This segment of emotional intelligence emphasizes logic in conjunction with what is felt and how one will respond to those feelings. In other words, female students were less likely to learn on intellect to "control or avoid the potential discomfort or ambiguity" found in various problems. One might find difficulty in saying female and male student will always differ significantly on their skills of emotional intelligence.

Age: Ogundokun and Adeyemo (2010) examined the moderating influence of emotional intelligence, age and academic motivation on academic achievement of secondary school students in Oyo State, Nigeria. Their findings showed that emotional Intelligence, age and academic motivation were potent predictors mildly associated with academic achievement.

Family Type: on family background, it is generally accepted that the quality of family interactions has important associations with children's and adolescents' academic motivation, achievement and feeling (emotions). Kellaghan and his colleagues (1993) claimed, for example, that the family environment is the most powerful influence in determining students' school achievement and academic motivation. Similarly, Coleman (1997) stated that, parents' involvement in learning activities has substantial emotional and intellectual benefits for children. He observed, however, that because supportive and strong families are significant for school success, teachers confront increasing challenges as many children experience severe family disruption and upheaval which may in turn affect the level at which such students assimilate in the class room. Although, it is acknowledged that families are perhaps the most substantial influence on children's school success, it is not always clear which family influences are the most important.

Level of Study: there is dearth of research in the area of level of study as it influences emotional intelligence of undergraduates. Attempts made to uncover related studies in this area have proved abortive. It is anticipated that the findings of this study will provide baseline data for research in the level of study as it affects emotional intelligence of undergraduates.

\section{METHOD}

\section{Research Design}

The research design adopted for this study was descriptive survey of the correlational type. According to Stangor (2004), correlational design is appropriate for measuring such complexities of the pattern of relationships that exists among measured variables. Correlational research design was preferred in this study because the design is capable of looking at the relationship between or among two or more variables. This is because 
the researcher was interested in finding out the influence of moderating variables on Nigerian undergraduates' emotional intelligence and attitude towards examination.

\section{Participants}

The population for this study comprised all undergraduates in Nigeria, which was estimated at 1,855,000: Federal Universities $=1,150,000$; State Universities $=400,000$; and Private Universities $=305,000$ (Annual Reports of Universities in Nigeria, 2016). The target population, on the other hand, consisted of all undergraduates in Federal Universities in six selected states across the six geopolitical zones of Nigeria. Based on the Research Advisors (2006), a total sample size of 1,536 was recommended at 95\% confidence and $2.5 \%$ margin of error. Based on this recommended figure i.e. 1,536 and for equal representation, 256 respondents were purposively selected from each of the six federal universities.

Purposive and stratified random sampling procedures were employed to select the respondents for the study. The techniques comprised several stages of selection from the larger sampling framework to the actual sample size for the study. In giving the study a national spread, the existing six geopolitical zones of the federation were used as the sampling field.

At stage one; the researcher adopted the purposive sampling technique to ensure a national spread by deliberately selecting a state from each of the six geo-political zones in Nigeria. Furthermore, one Federal University was purposively selected from each of the six selected States. Thus, a total of six Federal Universities were purposively selected. At stage two, stratified random sampling technique was employed to select participants for the study.

\section{Data Collection Tools}

Two questionnaires were used to collect the necessary data. In order to collect the data on emotional intelligence; Emotional Intelligence Scale (EIS) was adopted from Wong and Law (2002) to measure emotional intelligence. Wong and Law (2002) developed EIS based on summary of a perspective of emotional intelligence in the literature, which consists of four domains. These domains form the four sub-scales of the measure. Each sub-scale consists of four items. The items on the measure are self-rated on a 5- point Likert-type scale $(1=$ totally disagree to $5=$ totally agree $)$. The four scales of measure are Self-Emotion Appraisal (SEA), Others' Emotion Appraisal (OEA), Use of Emotion (UOE), and Regulation of Emotion (ROE). All items are positively keyed. A sample item from SEA is "I have a good sense of why I have certain feelings most of the time." A sample item from OEA is "I always know my friend's emotions from their behaviour." "I always set goals for myself and then try my best to achieve them" and "I have good control of my own emotions" are items from UOE and ROE respectively. The inter-scale correlations were mild to moderate in one sample $(\mathrm{r}=0.13-0.42)$ and higher in another sample ( $\mathrm{r}=0.60-0.76)$ (Wong \& Law, 2002). The ranges of coefficient alphas for the scales reported in various studies in Wong and Law's article were 0.860.92 for SEA, $0.82-0.93$ for OEA, $0.84-0.88$ for UOE, and $0.71-0.91$ for ROE. After subjecting the test to a split-half reliability test, it has a reported coefficient alpha of 
0.75 and a standardize item alpha of 0.73 . The researcher decided to adopt the EIS for use since it corresponds with the desired measure of the study. It is worthy to note that this scale (EIS) has been used in Nigeria by Agokei (2011) who investigated the effect of social cognitive training and mindfulness technique on self-efficacy and effectiveness of pre-service counsellors in Nigeria Universities.

To measure attitude towards examination, the instrument in this section was developed by experts in the Department of Counsellor Education, University of Ilorin (2013) but was adapted to suit the objective of this study. The Scale is made up of thirty-six (36) items with a 4-point Likert-type response format of " 1 " Not True of Me to "4" Very True of Me to which respondents indicate and reveal their relative agreements by a tick. The correlation co-efficient of the instrument after subjecting it to co-efficient of stability was reported at 0.73 co-efficient alpha. The researcher decided to adapt the ATES for use since it corresponds with the desired measure of the study.

The researcher modified some of the statements and adapted the scale into a twenty (20) item version. The researcher then determined the psychometric properties of this adapted version. To ascertain the validity of the scale, the researcher gave it to five lecturers in the Department of Counsellor Education, University of Ilorin for scrutiny and assessment. At the end of the exercise, the lecturers unanimously agree that the scale covered the domain of interest; thus justifying the content validity of the scale. A sample item from ATES is "I study very well before examination."

As for its reliability, the scale was administered to forty students of Kwara State University, Malete, Kwara State. After an interval of four weeks, the scale was readministered to the same respondents. The two sets of scores derived were then correlated using Pearson's Product Moment Correlation formula which yielded a coefficient of 0.88 . The scale with this relatively high coefficient of stability was therefore considered adequate and reliable for the study.

\section{Data Analysis}

The data collected were analysed by the researcher using descriptive and inferential statistical procedures. Pearson's Product Moment Correlation (PPMC) statistical technique was used to analyse hypothesis 1 and Multiple Regression was used to analyse hypothesis 2 at 0.05 level of significance.

\section{FINDINGS}

Hypothesis One:

There is no significant correlation between emotional intelligence and attitude of undergraduates towards examination in Nigeria

In order to test this hypothesis, participants' responses to the scales (Emotional Intelligence and Attitude of Undergraduates towards Examination) were collated. The data collected from the study were analysed using Pearson's Product Moment Correlation statistics. Summary of the analysis is presented on Table 1. 
Table 1

Correlation between Emotional Intelligence and Attitude of Undergraduates towards Examination

\begin{tabular}{lcccccc}
\hline Variables & $\mathrm{N}$ & Mean & SD & df & Cal. r-value & p-value \\
\hline Emotional Intelligence & 1536 & 62.93 & 7.76 & 1534 & $0.35^{*}$ & 0.003 \\
Attitude Towards & 1536 & 66.82 & 6.33 & & & \\
Examination & & & & & & \\
\hline
\end{tabular}

*Significant, $\mathrm{p}<0.05$

The result on Table 1 indicates that the calculated $\mathrm{r}$ is 0.35 and the $\mathrm{p}$-value is 0.003 . Since the calculated p-value is less than the alpha level at 0.05 , indicating a significant relationship. Hence, the hypothesis which states that there is no significant correlation between emotional intelligence and attitude of undergraduates towards examination was rejected. This means that there was a significant positive correlation between emotional intelligence and attitude of undergraduates towards examination.

Hypothesis Two: $\quad$ Gender, age, level of study, university and family type will not influence undergraduates' emotional intelligence and attitude towards examination in Nigeria

In order to test this hypothesis, participants' responses to the scales (Emotional Intelligence and Attitude of Undergraduates towards Examination) were collated. The data collected from the study were analysed using multiple regression statistics. Summaries of the analysis are presented on Tables 2 and 3.

Table 2

Analysis of Variance (ANOVA) Showing the Regression between the Predictors Variables and the Dependent Variable

\begin{tabular}{lccccc}
\hline Model & Sum of Squares & df & $\begin{array}{l}\text { Mean } \\
\text { Squares }\end{array}$ & $\begin{array}{l}\text { Cal. F- } \\
\text { ratio }\end{array}$ & p-value \\
\hline Regression & 15644.985 & 5 & 3128.997 & $24.99 *$ & $.000^{\mathrm{b}}$ \\
Residual & 191548.849 & 1530 & 125.195 & & \\
Total & 207193.834 & 1535 & & & \\
\hline
\end{tabular}

*Significant, $\mathrm{p}<0.05$

a. Dependent Variable: ATE

b. Predictors: (Constant), EI, Family Type, University, Age, Gender, Level of study

Table 3

Regression Co-efficient showing Gender, Age, Level of Study, University and Family Type Correlating with Undergraduates' Emotional Intelligence and Attitude Towards Examination

\begin{tabular}{llllll}
\hline Model & B & Std. Error & Beta & Cal t-value & p-value \\
\hline Constant & 137.738 & 2.001 & & 68.842 & .000 \\
Gender & 1.709 & .610 & .030 & 1.162 & .245 \\
Age & 2.590 & .604 & .026 & $7.977^{*}$ & .031 \\
Level of Study & 3.665 & .357 & .280 & $10.276^{*}$ & .000 \\
University & 1.383 & .167 & .056 & $2.287 *$ & .022 \\
Family Type & .522 & .669 & .021 & .781 & .435 \\
\hline
\end{tabular}


Table 2 shows the result of the ANOVA table indicating an F-ratio of $F(5,1530)=$ $24.99, \mathrm{p}<0.05$. This implies that the correlation between the predictors and outcome variables are statistically significant. Table 3 further expressed the result of the relative contribution of moderating variables (gender, age, level of study, university and family type) correlating with undergraduates' emotional intelligence and attitude towards examination. Gender have a Beta weight $(\beta)$ of $1.709, \mathrm{t}=1.162, \mathrm{p}>0.05$; age have a Beta weight $(\beta)$ of $2.590, \mathrm{t}=7.977, \mathrm{p}<0.05$. Level of study have a Beta weight $(\beta)$ of $3.665, \mathrm{t}=10.276, \mathrm{p}<0.05$; university type have a Beta weight $(\beta)$ of $1.383, \mathrm{t}=2.287$, $\mathrm{p}<0.05$; while family type have a Beta weight $(\beta)$ of $.522, \mathrm{t}=.781$. Age, university and level of study have a relationship with undergraduates' emotional intelligence and attitude towards examination. Therefore, hypothesis five which states that gender, age, level of study, university and family type will not influence undergraduates' emotional intelligence and attitude towards examination was hereby rejected.

\section{DISCUSSION}

Finding revealed that there was a significant positive correlation between emotional intelligence and attitude of undergraduates towards examination in Nigeria. This means that, the increase in emotional intelligence level will positively disposed students attitude towards examination. Since there is need to meet the demands and challenges of the modern life and in order to achieve this, students need to be emotionally stable. This finding corroborated the findings of Goleman (1995) who found that emotional intelligence principles link strongly to a person's attitude toward things, interpersonal skills, management styles and potential. People with strong emotional intelligence balance feelings with reason, logic, and reality.

Furthermore, Mansour and Morteza (2012); Adegboyega (2016) found that relationship between emotional intelligence and attitude to brokerage firms' performance in Tehran Stock Exchange was significant. Those with low emotional intelligence are usually rigid, inflexible, need rules and structure to feel secure. Thus, people with strong emotional intelligence do have a positive and balanced attitudinal view of situations while those with a weak emotional intelligence tend to have a negative and biased attitudinal view of situations (National Centre for Clinical Infant Programs, 2013).

Another finding revealed that gender, age, level of study, university and family type had a significant positive influence on undergraduates' emotional intelligence and attitude towards examination in Nigeria. This implies that the correlation between the predictors and outcome variables are statistically significant. This finding also agrees with the findings of Paul (1982) who stated that achievement oriented behaviour is a function of a number of factors including the motive to succeed, the motive to avoid failure, the perceived probability of success and the incentive value of success. All these are influenced by an individual's emotional state of mind. Students low on emotional intelligence may find failure more difficult to deal with, which thus undermines their academic motivation (Drago, 2004). 


\section{CONCLUSION}

Based on the findings of the study, the following conclusions were drawn:

There was a significant positive correlation between emotional intelligence and attitude of Nigerian undergraduates towards examination. Students with high emotional intelligence tend to have positive attitude towards examination. Also, moderating variables of gender, age, level of study, university and family type had a significant positive influence on undergraduates' emotional intelligence and attitude towards examination.

\section{IMPLICATIONS FOR COUNSELLING}

Results from this study have implications for counsellor training and practice. The implication of this finding for counsellor training is that counsellors need to be equipped with relevant skills and intensify efforts in guiding and counselling students on appropriate components of emotional intelligence, achievement motivation and attitude towards examination. When students become emotionally and socially intelligent, their attitude towards examination can be improved. Based on the findings of this study, it is feasible to continue to improve the attitude of students by encouraging them to: (i) be aware of their emotions; (ii) manage their emotions; (iii) use emotions to motivate themselves; (iv) recognize the emotions of other people; (v) effectively manage relationships; (vi) set and achieve personal goals and develop their potentials; and (vii) to be realistically positive and optimistic.

This study also has implication for counsellor practice. Counsellors with the cooperation of college managements and parents should endeavour to design appropriate intervention strategies to enhance the listed emotional intelligence factors related to students' attitude towards examination.

\section{RECOMMENDATIONS}

Based on the findings of the study, the following recommendations were made:

Professional counsellors should endeavour to help undergraduates in their institutions of learning by organizing seminars that will help them to understand the relationship between emotional intelligence and attitude towards examination within the tertiary institutions. These undergraduates can also be helped to identify their true position and attitude towards examinations as well as the need to set valuable targets for high academic attainment and they should thus be encouraged from time to time on the need to seek counselling in the area of goal setting for high academic achievement.

Students should continue to cultivate the habit of developing high emotional intelligence as it would help them to develop positive attitude towards examination, effective leadership skills such as improved communication among peers and other people, less school and workplace conflict, better problem solving skills and increased likelihood of promotions to greater heights. 
Lecturers should be equipped with the right information needed to assist students in determining the appropriate components of emotional intelligence to be developed as well as the appropriate achievement motivation goals to be set as a perceived strategy for high and improved academic performance in Nigerian tertiary institutions examinations.

\section{REFERENCES}

Aaron, R. M. (1992). Student academic dishonesty: Are collegiate institutions addressing the issue? NAPSA Journal, 29, 103-113.

Adegboyega, L. O. (2016). Relationship between emotional intelligence and attitude towards examination of undergraduates at University of Ilorin. Unpublished seminar paper, Department of Counsellor Education, University of Ilorin, Ilorin, Nigeria.

Annual Reports of Universities in Nigeria (2016). Population of undergraduate students in Nigeria.

Ajzen, I. (2001). Nature and operation of attitude. Annual Review Psychology, 52, $27-$ 58 .

Allport, G. W. (1935). Attitudes. Handbook of social psychology. In C. Murchison (Ed.), Worcester, Mass: Clark University Press.

Aremu, A. O. (2004). Psychological and sociological determinant of academic achievement of Nigeria adolescents. Ife Psychologia, International Journal of Psychology in Africa, 12(2), 149-161.

Bernet, M. (1996). Emotional intelligence: Components and correlates. Paper presented at the annual meeting of the American Psychological Association, Toronto.

Caruso, D. R., \& Salovey, P. (2004). The emotionally intelligent manager: How to develop and use the four key emotional skills of leadership. San Francisco: Jossey-Bass.

Cherniss, C., \& Goleman, D. (2003). The emotionally intelligent workplace: How to select for, measure, and improve emotional intelligence in individuals, groups, and organization. $1^{\text {st }}$ edition Foreword by Warren Bennis or San Francisco; Jossey-Bass business \& management series

Coleman, M. F. (1997). The role of parental interaction in achievement motivation. The Journal of Social Psychology, 133, 859-861.

Dilard, J. P. (1994). Rethinking the study of fear appeals: An emotional perspective. Communication Theory, 4(4), 295-323.

Drago, J. M. (2004). The relationship between emotional intelligence and academic achievement in non-traditional college students. Doctoral Dissertation, Walden University. 
Eagly, A. H. \& Chaiken, S. (1998). Attitude structure and function. In D. Gilbert, S. Fiske, \& G. Lindzey (Eds). The Handbook of Social Psychology $\left(4^{\text {th }}\right.$ ed. Vol. 1, pp. 269322). New York: McGraw-Hill.

Feyerherm, A. E., \& Rice, C. E. (2002). Emotional intelligence and team performance: The good, the bad and the ugly. International Journal of Organizational Analysis, 10(4), 343-363.

Goleman, D. (1995). Emotional intelligence. New York: Bantam Books.

Goleman, D. (1998). Working with emotional intelligence. New York: Bantam Books.

Goleman, D. (2001). Emotional intelligence: Issues in paradigm building. In Goleman, D. \& Cherniss, C. (eds.) The Emotionally Intelligent Workplace: How to Select for, Measure, and Improve Emotional Intelligence in Individuals, Groups, and Organization. San Francisco, CA: Jossey-Bass.

Goleman, D. (2004). Never stop learning. Harvard Business Review, 82(1), 28-30.

Goswami, U. (1991). Analogical reasoning: What develop? A review of research and theory. Child Development, 62(1), 1-22.

Kafetsios, K. (2004). Attachment and emotional intelligence ability across the life course. Personality and Individual Difference, 37, 129-145.

Luebbers, S., L., \& Downey, A. et al. (2007). The development of an adolescent measure of EI. Personality and Individual Differences, 42, 999-1009.

Macaluso, J. C. (2003). Leading with empathy. Executive Excellence, 20(7), 9-15.

Mansour, G., \& Morteza, M. (2012). Examining the relationship between emotional intelligence and attitude to brokerage firms'performance in Tehran Stock Exchange. International Research Journal of Applied and Basic Sciences, 3(4), 886-890.

Mendezabal, M. J. N. (2013). Study habits and attitudes: The road to academic success. Open Science Repository Education, Online (open-access), e70081928.doi: 10.7392/Education.70081928.

Miller, N. B., Silverman, L. K., \& Falk, R. F. (1994). Emotional development, intellectual ability, and gender. Journal for the Education of the Gifted, 18, 20-38.

Mituka, B. (2001). Exam cheating: Top officials sacked. The Kenya Times Newspapers, p. 15.

Nanna, E. M. (1997). Teacher's behaviour amongst school pupils as a factor in examination malpractice in secondary school: A study of schools in Ughelli North Local Government Area of Delta State. Unpublished Bachelor of Education Project, Ambrose Alli University, Ekpoma, Nigeria.

National Centre for Clinical Infant Programs (2013). Zero to three gains a new initiative, Project LAUNCH (Linking Actions for Unmet Needs in Children's Health); Project LAUNCH is a state, tribal and community-based focal point for early childhood 
systems development funded by the Substance Abuse and Mental Health Services Administration (SAMHSA).

Nelson, D., \& Low, G. (2003). Emotional intelligence: Achieving academic and career excellence. Upper Saddle River, PA: Prentice Hall.

Nuthana, P. \& Yenagi, G. (2009). Influence of study habits, self-concept on academic achievement of boys and girls. Kartanaka Journal of Agricultural Science, 22(5), 1135 1138 .

Ogundokun, M. O., \& Adeyemo, D. A. (2010). Emotional intelligence and academic achievement: The moderating influence of age, intrinsic and extrinsic motivation. The African Symposium: An Online Journal of the African Educational Research Network, 10(2), 127-141.

Ongeri, J. D. (2009). Learner-centered teaching in economics: An action research study. A Dissertation in Adult Education, College of Education, The Graduate School, The Pennsylvania State University.

Papalia, G. (2004). Imaginary colonies: Fascist views of Australia in Italian diplomatic correspondence 1922-1940. Eras Journal 6, Accessed 18 September 2005. Available from: http://www.arts.monash.edu.au/eras/edition_6/papaliaarticle.htm.

Parker, J. D. A., Creque. Snr. R. E., Barnhart. D. L., Harris. J. I., Majeski. S. A., Wood, L. M., et al., (2004). Academic achievement in high School: Does emotional intelligence matter? Personality and Individual Differences, 37(7), 1321-1330.

Peterson, C., Selgman, M. E., \& Vaillant, G. E. (1988). Pessimistic explanatory style is a risk factor for physical illness: A thirty-five-year longitudinal study. Journal of Personality and Social Psychology, 55(1), 23-27.

Porter, J., \& Stone, K. (1995). The effect of leader and follower emotional intelligence on performance and attitude: An exploratory study. The Leadership Quarterly, 13, $243-$ 274.

Porterfield, J., \& Kleiner, B. H. (2005). A new era: Women and leadership. Equal Opportunities International, 24(5/6), 49-57.

Research Advisors (2006). Sample size table: Required sample size. http://www.research-advisors.com/tools/samplesize.

Salovey, P. \& Mayer, J. D. (1990). Emotional intelligence. Imagination, Cognition and Personality, 9(3), 185-211.

Six Seconds, Emotional Intelligence Network (2013). http://www.6seconds.org/2013/04/24/fog- how-to-use-emotional-intelligence-freeposter/.

Stangor, C. O. (2004). Research methods for behavioural sciences. Boston: Houghton Mifflin Co. 
Surtaso, T., \& Toto, B. (1996). Effect of gender and GPA on emotional intelligence. Paper Presentation at the Annual Meeting of the Mid-South Educational Research Association, Tuscaloosa, AU.

Van Bavel, J. J., Xiao, Y. J., \& Cunningham, W. A. (2012). Evaluation as a dynamic process: Moving beyond dual System models? Social and Personality Psychology Compass, 6(6), 438-454.

Vitello-Cicciu, J. (2003). Innovative leadership through emotional intelligence. Nursing Management, 34(10), 28-32.

Wong, C., \& Law, K. S. (2002). The effects of leader and follower emotional intelligence on performance and attitude: An exploratory study. The Leadership Quarterly, 13(3), 243-274. 